\title{
Dr. Leggo: A Legend
}

\author{
Karen V. Lee, The University of British Columbia \\ kvlee@,mail.ubc.ca
}

\begin{abstract}
The author reflects on the death of professor who was on her doctoral committee. She considers how "grief and bereavement has undergone a transformational change in terms of how the human experience of loss is understood" (Hall, 2014, p. 7). The article explores how "poems are powerful documents that possess the capacity to capture the contextual and psychological worlds of both poet and subject" (Furman et al., 2007, p. 302). It also explores how reflexivity can be enacted through a poetic inquiry (Prendergast et al., 2009). Thus, the narrative can contextualize "using alternative forms of data to evoke deep and powerful emotional reactions in the consumer of research" (Denzin, 1997). In the end, the narrative weaves poetic inquiry that helps the author gain a deeper understanding about grief and how it transforms reflections on death, dying, life, and loss.
\end{abstract}

Keywords: Death; Grief; Loss; Poetic Inquiry.

\section{Introduction}

I

n 1996, my life as a doctoral student changed when I met Dr. Carl Leggo who was the professor instructing a graduate course on narrative studies in department of LLED at UBC. He spoke poetic words that lit many faces during each class. A guru of verse, he inspired and moved my graduate studies toward arts-based research. My doctoral dissertation became a narrative of short stories that featured my students transitioning from musicians to teachers. Wholeheartedly, Carl supported this research and was instrumental in having me share arts-based educational research (ABER) with music teachers. I am forever grateful for his words of encouragement that stirred me through the writing and defense of my doctoral dissertation.

After his passing in March 2019, I had to "shift away from the idea that successful grieving requires letting go of the deceased, and a move towards a recognition of the potentially healthy role of maintaining continued bonds with the deceased" (Hall, 2014, p. 7). In maintaining a bond for Carl, I have written some poetry for his tragic death as "our texts must always return to and reflect the words persons speak as they attempt to give meaning and shape to the lives they lead" (Denzin, 2014, p. 4). I wish to explore the nature of poetry as a tool of qualitative research for investigating human phenomena (Furman et al., 2007, p. 1). I explore the poetry as a grieving tool to move towards the "cognitive, social, cultural, and spiritual dimensions of grief and loss" (Hall, 2014, p.7) and reflect upon the powerful influence Carl had on my academic career along with severe loss and terrible emptiness his passing brought to the scholarly university community. 
I wither like a leaf

From heavy gape chest

A theme of words

Of shadows and shapes

I wither like a leaf

From fateful echoes

A coffin and a Chevy

Of mourning memos

I wither like a leaf

From his textual power

A landscape of color

Of poetic wonder

I wither like a leaf

From rhyming songs

A mournful hymn

Of drone of gone

I wither like a leaf

From reviving his lyrics

A hope and tenderness

Offilling his emptiness

To Carl, the mentor. To Carl, the orator. Everything has changed. I pass each day with your memory in serious and inconsequential chatter. A friend who had you as her graduate advisor phones in tears about your passing. We want to wash up beside you, dust along you, and hear your voice orate yet another beautifully poetic reading. We miss your breath that falls like the parchment upon wind. We miss the happy place where you were an extraordinary teacher and mentor. Instead, we drown in flowers, wild masses of foliage against our flesh. A splash of ocher edge lies within a deep translucent backdrop of color. The fermented aroma brings a musty odor. Only grey eyes, dim with age, sit under cobwebbed vaults from the ceiling. A blank white wall is shaken by the image of your death.

The last few months, I tell myself these things pave way for future insights. But words cannot bring meaning to your passing. The sickness that ate through your flesh during the shadowy afternoon you died. In the dense darkness of days, you lived a senseless time in the hospital.

I welcome this afternoon to grieve. No-one to disturb me. I brew Tie guan yin tea and sip it slowly in my kitchen. You were interested in how we tell the stories we tell. Leggo the legend. Here, surrounded by objects, I see the need to ponder and linger over your words. Many books of poetry you wrote that pierced our hearts. A true legend. Forgive me, Carl as it's rather painstaking to write about your passing. A grand excuse for passionate writing without your guidance. When sickness took over, you still emailed me writing ideas from your hospital bed. You gave extreme rarity value to my writerly life and yet I cannot lie but admit it is a challenge to continue to write without your guidance. It is paralyzing to parachute out of my own free will to write. 
I cut a slice of peach in hopes it would be cathartic. My usual confessional is straight fruit, not Captain Morgan Rum. But better to crisis in the evening. It's 6pm with a cup of tea and piece of peach. His long, brown, wavy hair, dark eyes, after five shadow, and high forehead. A prosaic poet with large amounts of phraseology. There could not be a more distressing moment than thinking Carl got a brain tumor and died. Drowning in a sea of inevitability. Downright depressing and heartbreaking.

Staring into the tea leaves, I pretend to be 'consultant.' I take the cup by the handle in the left hand, rim upwards and circle 3 times from left to right so the tea leaves cling to the sides while others slide to the bottom. Drain the liquid away. Diligently, I wish for my future destiny. If I see dots, it indicates money. But no dots. None. Do I see letters? Yes, I see only L for Leggo.

I want to break into run but don't. Instead, walk like someone who is empty inside. Expressionless, I hide behind an air of resignation. A thin sunlight breaks through the window blinds but tears and more tears, I know life is fragile. People die and I have to go on.

Now, you are a hundred miles away. If I call your name, would you answer? But I count the days until your university celebration titled, "The Many Faces of Love: Celebrating the Lifework of Carl Leggo." Bitter cold days filled with a steady budding of peace lilies. I have five lilies in my home that are happy and healthy. From white and off-white fragrant flowers that bloom, they have elegant dark green leaves. They signify calm, balance, rebirth. For some reason, I become autistically stuck on these lilies hoping for your rebirth. Highly unlikely as your death should have been avoidable. Grief, like death, is both meaningful and meaningless. Words cannot embrace grief that has gathered the faces of an entire generation who knew you from the lingering of your lyrics. It is totally absurd to say you died. I'm so sorry for your death. Sorry.

Alone
I miss his words
Light becomes dark
I lie on the couch
Sleep
Sorry
How are you doing
I'm not okay
Please return
I stand
Sorry
Step forward
Start to speak
I cannot
Start to cry
Sorry

\section{Epilogue}

This article explores the use of narrative and poetry as a means of data representation when grieving over the loss of a prominent professor. Furman (2005) demonstrates how using different poetic forms in conjunction with traditional data analysis methods can lead to the development of 
data that are both highly consumable and emotionally evocative. It shares how "poetry has become an increasingly valuable tool for social investigators utilizing expressive arts (Furman, 2004a, 2004b, 2004c; Langer and Furman, 2004a). It is hoped that a poetic response to the poetic data would represent the grief from Dr. Leggo's death. While poems can address the experience of the author, "they have the capacity to sensitize readers to existential themes that are often shared by many people," (Furman, , Langer, Davis, Gallardo, Kulkarni, 2007, p. 303).

Overall, expressing the murky waters of grief through poetic inquiry can highlight inner and outer experiences that show, hint, tease, captivate and resonate with readers while presenting and embracing criticality through the artistic medium of poetry. Leavy (2015) wrote, “...poetry is a form that itself brings attention to silence (or as a poet might say, to space) and also relies on emotional evocation as part of meaning making while simultaneously exposing the fluidity and multiplicity of meaning" (p. 66). Thus, I end on words from Leggo, "as one who is left behind, my calling is to remember. . . and to share stories . . . but my calling is also to explore connections between life and loss, and the possibilities that extend beyond loss" (Leggo, 2017, p. 77).

\section{References}

Denzin, N. K. (1997). Interpretive ethnography. Sage Publications, Inc.

Denzin, N.K. (2014). Interpretive autoethnography. Sage Publications, Inc.

Furman, R., Langer, C., Christine, D., Gallardo, H., and Kulkarni, S. (2007). Expressive research and reflexive poetry as qualitative inquiry: A study of adolescent identity. Qualitative Research, 7(3), 301-315.

Hall, C. (2014). Bereavement theory: Recent developments in our understanding of grief and bereavement. Bereavement Care, 33(1), 7-12. https://doi.org/10.1080/02682621.2014.902610

Leavy, P. (2010). A/r/t: A poetic montage. Qualitative Inquiry, 16(4), 240-243. https://doi.org/110.1177/1077800409354067

Leggo, C. (2017). The faces of loss: The curriculum of loss. Journal of the Canadian Association for Curriculum Studies, 15(2), 1-14.

Prendergast, M., Leggo, C., and Sameshima, P. (2009). Poetic inquiry: Vibrant voices in the social sciences. Sense Publishers. 